\title{
Cenplestao
}

\section{Uma análise de domínio da área de Organização e Representação do Conhecimento no contexto do periódico Em Questão}

\author{
Thiago Henrique Bragato Barros \\ Doutor; Universidade Federal do Rio Grande do Sul, Porto Alegre, RS, Brasil \\ bragato.barros@ufrgs.br; ORCID: https://orcid.org/0000-0001-7439-5779; \\ Rita do Carmo Ferreira Laipelt \\ Doutora; Universidade Federal do Rio Grande do Sul, Porto Alegre, RS, Brasil \\ rita.laipelt@ufrgs.br; ORCID: https://orcid.org/0000-0002-7429-8490;
}

\begin{abstract}
Resumo: Este artigo tem como objetivo mapear, analisar tematicamente, semanticamente e discursivamente os artigos da área Organização do Conhecimento publicados na Revista Em Questão desde sua migração para o sistema digital SEER em 2003. As categorias temáticas para a classificação dos artigos foram obtidas a partir de uma análise de domínio. As categorias para a classificação dos artigos foram obtidas a partir de uma análise de domínio, com enunciados-pivô da área da Organização do Conhecimento, inseridos na base de dados da revista. A partir de um corpus de 30 textos, utilizou-se o software Sketch Engine como um procedimento semântico-discursivo que auxiliou na organização do domínio a partir das abordagens temática, epistemológica, terminológica e discursiva. Como resultado, organizou-se uma linha do tempo das temáticas da organização do conhecimento publicadas com maior frequência ao longo dos anos 2000 o periódico, que indicou uma produção incrementada da área de organização do conhecimento a partir de 2014, bem como maior relação semântica entre termos e conceitos da comunidade analisada.
\end{abstract}

Palavras-chave: Organização do Conhecimento; Análise de Domínio; Semântica; Em Questão

\section{Introdução}

Tomando por base os preceitos conceituais estabelecidos por Hjørland (2017) e Smiraglia (2015) sobre a análise de domínio enquanto um estudo dos aspectos teóricos de dado entorno, representado, muitas vezes, por meio de uma literatura, uma comunidade científica/discursiva, busca-se, com esse estudo, evidenciar as relações temáticas, temporais, semânticas e discursivas ao longo dos números da revista Em Questão no contexto dos artigos provenientes da 
área de organização do conhecimento: qual é a comunidade, quais são suas principais temáticas e regularidade de produção.

Para tanto, o presente trabalho verifica como se efetiva essa aproximação analisando a presença das temáticas da Organização do Conhecimento no contexto de publicação da revista a partir de 2003, quando a revista passou a ser publicada digitalmente, apresentando uma crescente de artigos provenientes da área de Ciência da Informação. A partir de uma análise de domínio em sua abordagem epistemológica e terminológica-discursiva, busca-se identificar os marcos teóricos que fundamentam os trabalhos da área no contexto da revista Em Questão. Esta análise busca contar a história deste campo no âmbito das publicações da revista.

De acordo com Tennis $(2003,2013)$ antes de pensar em uma análise de domínio, é necessário definir a área de estudo, o escopo da análise e seu propósito. Este exercício já foi feito aqui logo de início, a fim de atender essa premissa básica da análise proposta, sinalizando o escopo, método e propósito.

Além da filiação aos estudos de domínio da organização do conhecimento, gostaríamos de destacar que o exercício de análise feito a partir da comunidade do periódico Em Questão trata-se de uma vontade metodológica dos autores de apresentar uma análise semântica, ou seja, qualitativa do corpus levantado. Estudos dessa natureza no campo da Ciência da Informação (CI) ainda são escassos aparecendo com maior frequência no campo da Linguística, por meio da linguística de corpus, por isso acredita-se que essa seja nossa maior contribuição.

A escolha do periódico acontece como parte das atividades de comemoração e pesquisa devido aos 35 anos da revista, indexada em várias bases de dados, representando um marco para o desenvolvimento da comunicação científica no âmbito brasileiro em Ciência da Informação.

\section{Organização do Conhecimento}

A ORC (Organização e Representação do Conhecimento) enquanto campo representa uma especialização à Ciência da Informação, ou seja, é um palco de estudo institucionalizado socialmente e cientificamente dentro da área de 
Ciência da Informação para discutir teorias e metodologias relacionadas aos vários processos de representação e organização; “[...] a organização do conhecimento [...] como um campo distinto, considerado hoje como uma subárea (ou com um link com a Ciência da informação)." (MAZZOCCHI, 2018, p. 54, tradução nossa)

Ela é, portanto, um campo que buscará estudos sobre os aspectos da construção tesauros, vocabulários controlados, taxonomias, ontologias, ou seja, uma gama de instrumentos e processos que visam à busca e apropriação do conhecimento, tradicionalmente ligada à Ciência da Informação, porém, mesmo com esse viés vinculante com a CI tem a atuação de profissionais de outras áreas do conhecimento como da Linguística, Computação, Psicologia e outros.

Assim, os processos tradicionalmente vinculados à $\mathrm{ORC}$, evidentemente, estão atrelados às bibliotecas e à informação para a ciência. Nesse sentido, os processos de leitura, análise e construção de linguagens especializadas estão, em sua maioria, relacionados a esse universo, porém, conforme a própria trajetória da ORC, a maior preocupação é o conteúdo e sua representação. Portanto, o trabalho da condensação documentária, fundamenta-se numa análise terminológica e discursiva dos domínios analisados.

A definição de uma ideia impacta no direcionamento que é dado ao desenvolvimento de pesquisas, um conceito em seu uso especializado pode determinar um domínio e um campo científico, esse é o caso da OR, quando estamos falando do conceito de organização e o conceito de conhecimento.

Assim, por um lado, a definição dos conceitos de conhecimento e de organização do conhecimento torna-se essencial para a fundamentação e entendimento do campo da organização. O processo de construção desta área pode ser fundamentado nestes autores, com base em Mazzocchi (2018) de Cutter (1837-1903), Richardson (1860-1939), Sayers (1881-1960) e, também de, Bliss (1870-1955), que usou o termo Knowledge Organization em dois importantes livros, The Organization of Knowledge and the System of the Sciences, datado 1929, and The Organization of Knowledge in Libraries and the Subject-Approach to Books, de 1933. 
Dahlberg deve ser sempre citada como uma pesquisadora que institucionaliza as práticas (discursivas) no campo da ORC. É o caso de textos do final dos anos 1970 e 1980, relacionados às questões conceituais da organização do conhecimento humano e o desenvolvimento da teoria do conceito.

Brascher e Café (2010) expõem que a organização do conhecimento é um sistema mental que reside no campo das ideias, é a forma que os indivíduos apreendem a realidade por meio de sistemas de cognição e de representação. Ao comunicar-se e interagir com a realidade, o indivíduo realiza atividades cognitivas de categorização das formas apreendidas resultando em uma modelagem desse conhecimento. Essa organização mental do conhecimento cria condições para que o indivíduo possa constituir uma significação lógica da realidade.

Já no universo de atuação da Organização do Conhecimento de acordo com Hjørland (2008), dois grandes grupos de ferramentas-processos podem caracterizá-lá, são eles: (1) processos de ORC, indexação, catalogação, análise de assunto, classificação; (2) sistemas de Organização e Representação do Conhecimento, gerados para esses processos. Sendo os sistemas primordiais à efetiva organização.

Nos Sistemas de Organização do Conhecimento (SOC) tendo por base Mazzocchi (2018) e Hjørland (2008), percebe-se que os sistemas são fundamentais à organização, porém um dos principais problemas se dá pela mudança rápida nas comunidades discursivas e seus domínios. Essa difícil tarefa, de representar o conhecimento, comum aos SOC é uma das maiores tarefas para seu desenvolvimento.

Em suma, SOC é um termo utilizado para um campo vasto de itens, dentre eles as ontologias, os cabeçalhos de assunto, os tesauros e os esquemas de classificação. Tendo cada um deles uma função e um fundamento tecnológico distinto e usado em uma variedade de agrupamentos sociais. Seu objetivo final é cumprir com a missão da própria Organização do Conhecimento: facilitar a navegação, disseminação e acesso. 
Acredita-se, aqui, portanto, em uma ORC integradora que vise contribuir para além de seu próprio campo de atuação, tendo em vista auxiliar na construção de melhores sistemas de organização do conhecimento. Hodge (2000) endossa essa perspectiva:

O termo sistemas de organização do conhecimento destina-se a englobar todos os tipos de esquemas para organizar informações e promover a gestão do conhecimento. Sistemas de organização do conhecimento incluem esquemas de classificação que organizam materiais em um nível geral (como livros em uma prateleira), cabeçalhos de assunto que fornecem acesso mais detalhado e arquivos de autoridade que controlam versões variantes de informações importantes (como nomes geográficos e nomes pessoais). (HODGE, 2000, p.1, tradução nossa)

SOCS também incluem esquemas menos tradicionais, como redes semânticas e ontologias. Como os sistemas de organização do conhecimento são mecanismos para organizar informações, eles estão no centro de todas as bibliotecas, museus e arquivos.

Tomando por base a teoria do conceito, Dahlberg (2006) aponta que a representação do conhecimento é baseada em unidades de conhecimento, que são os conceitos. Portanto, é basilar a análise dos conceitos, seus significados, relações semânticas e delimitações terminológicas de forma a permitir uma representação do conhecimento coerente com o domínio a que se refere, ou seja, a representação do conhecimento estará limitada a um determinado contexto e objetivo, representando, portanto, apenas uma parte da realidade, ou seja, um dado domínio de conhecimento. A ORC busca, então, trabalhar de forma aprofundada com a elaboração de sistemas, visando à representação de um determinado domínio.

Hjørland e Albrechtsen (1995) formularam a análise de domínio como uma nova abordagem da Ciência da Informação. No artigo é enfatizada a natureza social, ecológica e a orientação para o conteúdo do conhecimento em oposição às abordagens mais formais, semelhantes às discussões da engenharia de software, que dominaram na década de 1980. No mesmo artigo é afirmado que o horizonte mais produtivo para a organização seria o estudo dos domínios do conhecimento como comunidades de pensamento ou discurso, que são partes da divisão do trabalho da sociedade. Desde então, esses objetivos representaram 
as principais características da análise de domínio, algo a ser problematizado na próxima seção em que articulamos com o campo da Ciência da Informação.

Na seção seguinte será abordado a análise de domínio enquanto aporte metodológico.

\section{Análise de Domínio enquanto aporte metodológico para a Ciência da}

\section{Informação}

A análise de domino desde sua discussão inicial no contexto da Ciência da Informação na década de 1990 desenvolveu-se e assumiu características próprias que foram sendo revisitadas e redesenhadas.

Por uma questão de relembrar essa trajetória, são essas as 11 abordagens iniciais, propostas por Hjørland (2017) que, depois, foram revistas por Smiraglia (2015) e Guimarães e Tognoli (2015).

1. Produção e avaliação de guias de literatura e gateways de assunto;

2. Produção e avaliação de classificações especiais e tesauros;

3. Pesquisa sobre competências em indexação e recuperação de informações em especialidades;

4. Conhecimento de estudos empíricos com usuários em áreas temáticas;

5. Produção e interpretação de estudos bibliométricos

6. Estudos históricos de estruturas de informação e serviços em domínios;

7. Estudos de documentos e gêneros em domínios do conhecimento; 8. Estudos epistemológicos e críticos de diferentes paradigmas, pressupostos e interesses em domínios;

9. Conhecimento de estudos terminológicos, LSP (linguagens para fins especiais) e análise de discurso em campos do conhecimento; 10. Estudos de estruturas e instituições em comunicação científica e profissional em um domínio;

11. Conhecimento de métodos e resultados de estudos analíticos de domínio sobre cognição profissional, representação de conhecimento em ciência da computação e inteligência artificial (HJØRLAND, 2017, tradução nossa).

Tomando por base Hjørland (2017) fica claro que esses pontos incluem nos estudos dos domínios a própria organização do conhecimento, as 11 abordagens enfaticamente se relacionam a Ciência da Informação o objeto de estudo social, institucional da informação. Elas são uma mescla de atividades que são realizadas ou sugeridas pelos profissionais da informação e abordagens teórico-metodológicas de estudos. 
No estudo de Smiraglia (2015), ele revisou essas 11 abordagens, deixando de fora da indexação a abordagem 03, reescrevendo a abordagem 10 e adicionando, ainda sem uma reflexão mais aprofundada, semântica e análise do discurso, como uma abordagem da análise de domínio, reflexão mais aprofundada a respeito disso foi feita por Barros (2021). Guimarães e Tognoli (2015), adicionam a proveniência arquivística como uma abordagem da análise de domínio, temática já discutida em outros artigos que aproximam organização conhecimento e arquivologia (BARROS; SOUSA, 2019a, 2019b).

Smiraglia (2015) ao analisar 100 textos da área de informação, que de alguma forma trabalharam com a análise de domínio, demonstrou que que hoje análise de domínio é aceita e referenciada como um olhar metodológico importante para o estudo dos domínios científicos dentro e fora do campo da informação.

Assim, a análise de domínio pode ser compreendida como uma teoria e uma abordagem para CI e ORC, no caso da ORC abarcando a construção de sistemas e seus respectivos processos. O domínio em sentido estrito sempre esteve presente na CI, com outras terminologias como é o caso do conceito de "assunto", neste sentido domínio representa ao mesmo tempo uma especialização e um refino desse conceito para além da realidade dos processos de organização da informação em si.

Neste sentido, o presente texto filia-se aos estudos em análise de domínio buscando construir uma análise por meio da abordagem epistemológica, discursiva e semântica bem como uma análise baseada nas abordagens 6 e 10 .

\section{Procedimentos metodológicos}

Tomando por base o texto de Mai (2005) um domínio pode ser entendido, como uma especialidade, um conjunto de pessoas que trabalham em prol de um objetivo específico, ou seja, um agrupamento que possui substância e é definido em uma conjuntura institucional. No caso deste artigo, a comunidade de autores da revista Em Questão ao longo de sua história configura-se como uma comunidade, na qual buscamos trabalhar especificamente com a área de ORC, 
que desde 2003 publicou algum trabalho a respeito das temáticas da área, entendendo a ORC como uma área nuclear da Ciência da Informação.

Portanto, considera-se a análise de domínio enquanto um paradigma teórico e metodológico na organização do conhecimento (SMIRAGLIA, 2015). Conforme anteriormente destacado, combinamos nesta analise a abordagem semântico-discursiva em seus aspectos histórico, semântico e epistemológico a fim de evidenciar graficamente os aspectos semântico-discursivos que, aqui, utilizamos. Assim, partir de procedimentos semântico-discursivos com aporte em critérios como tema, contexto discursivo e tempo. Dessa forma, evidenciamos graficamente a análise por meio de lexigromas, quadros e gráficosDo ponto de vista da categorização, utilizou-se das categorias que representam as três dimensões de pesquisa que caracterizam a construção cientifica da área de OC: epistemológica, aplicada e cultural (relacionados aos aspectos sociais, políticos, econômicos, éticos). Conforme estabelecido historicamente no contexto da Internacional Society for Knowledge Organization (ISKO).

Foram analisados 30 artigos publicados entre 2003 e 2021. O recorte temporal a partir de 2003 foi realizado tendo em vista a mudança da revista Em Questão para a versão digital neste período.

Como enunciados-pivô utilizou-se os conceitos de "Indexação", "Organização do Conhecimento", "Organização da Informação", "Sistemas de Organização do Conhecimento", "Representação Documental”, "Representação do Conhecimento", "Representação da Informação" "Representação e Organização do Conhecimento", "Taxonomia", "Tesauro" e "Ontologia", nos títulos, resumos e palavras-chave tratando-se por tanto de uma análise de domínio descritiva e semântica conforme Ørom (2003).Os termos foram selecionados dado a importância deles do ponto de vista da elaboração dos conceitos da área de ORC, pois, estão presentes como termos fundamentais em dicionários especializados (BARITÉ, 2001).

Já em relação a categorização focou-se nas três dimensões de pesquisa que caracterizam a construção cientifica da área de ORC notadamente a epistemológica, aplicada e cultural (relacionados aos aspectos sociais, políticos, 
econômicos, éticos). Conforme estabelecido historicamente no contexto da ISKO.

Com base nos títulos, resumos e palavras-chave, identificamos as temáticas mais recorrentes e as possíveis correntes de pesquisa no âmbito da OC, utilizando da ferramenta de análise sintático-semântica Sketch Engine, que auxilia na construção dos agrupamentossemânticos, bem como quadros temáticos, históricos, dados de autoria e grafos para ilustrar o domínio estudado.

\section{Análise de resultados: análise de domínio da Em Questão no contexto da} organização do conhecimento

Dando início as análises, do ponto de vista do corpus levantado a Em Questão entre 2003 e 2021 publicou 876 textos, deste total 30 textos são da área de Organização e Representação do Conhecimento, uma porcentagem de $3 \%$.

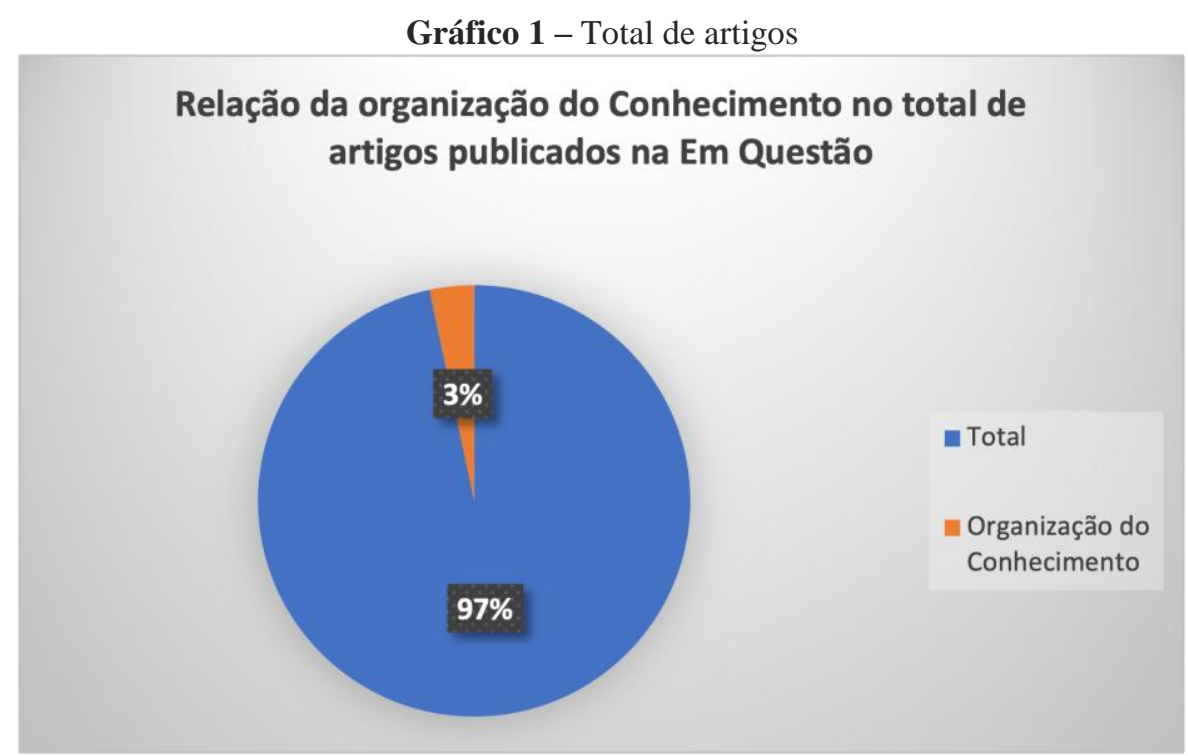

Fonte: Elaborado pelos autores.

Procedendo a análise e tendo em vista as dimensões da organização do conhecimento, a maioria dos textos trata-se da dimensão aplicada e da dimensão epistemológica (97\%), com o resultado de 17 textos para a dimensão aplicada (57\%) e 12 textos para a dimensão epistemológica (40\%). O que pode ser conferido no gráfico abaixo 




Fonte: Elaborado pelos autores.

Conforme é possível visualizar no gráfico 2, encontramos apenas um texto da dimensão cultural na revista Em Questão, repetindo, neste periódico, um resultado também encontrado em outras comunidades (Tognoli, Silva e Silva, 2019; Evangelista, I. V.; Barros, T. H. B.; Moraes, J. B. E, 2018). O primeiro analisou as revistas Knowledge Organization e Scire, do ponto de vista da arquivologia e organização do conhecimento, e o segundo analisou a dimensão cultural nos anais da ISKO internacional. Estando também de acordo com Guimaraes (2014), quando fala da análise de domínio como uma abordagem metodológica para a área de organização. Logo, talvez esse seja um indício de que a dimensão cultural não está sendo discutida pelos autores/pesquisadores brasileiros da área de organização do conhecimento.

Relacionando os artigos com os enunciados-pivô selecionados no início da análise, construímos os quadros a seguir que organizam tematicamente os trabalhos. Ficam evidentes temáticas recorrentes no âmbito da organização do conhecimento tais como: análise de sistemas aplicados a domínios específicos, sistemas de organização do conhecimento, estudos métricos direcionados para a área de organização do conhecimento, a indexação enquanto um processo e uma teoria, aplicações em relação a tesauros, ontologias e taxonomias, bem como, estudos recentes relacionado à arquivologia e organização do conhecimento em ambas as dimensões. Portanto, a revista Em Questão representa a comunidade 
brasileira da área de organização do conhecimento com temáticas recorrentes em outros periódicos nacionais e internacionais.

O primeiro quadro diz respeito a análise de domínios específicos por intermédio de preceitos da organização do conhecimento, neste caso destacamse textos oriundos da documentação jurídica.

Quadro 1 - Artigos da dimensão aplicada Análise de Domínios específicos

\begin{tabular}{|c|c|c|}
\hline Título & Autor & Ano de Publicação \\
\hline $\begin{array}{l}\text { Análise de assunto de } \\
\text { acórdãos jurisprudenciais }\end{array}$ & $\begin{array}{c}\text { Ana Carolina Ferreira; } \\
\text { Benildes Coura Moreira } \\
\text { dos Santos Maculan }\end{array}$ & 2018 \\
\hline $\begin{array}{l}\text { Metodologia para a análise } \\
\text { de assunto de acórdãos no } \\
\text { contexto do controle } \\
\text { externo: proposta de um } \\
\text { modelo de leitura técnica }\end{array}$ & $\begin{array}{c}\text { Ana Carolina Ferreira, } \\
\text { Benildes Coura Moreira } \\
\text { dos Santos Maculan }\end{array}$ & 2019 \\
\hline $\begin{array}{c}\text { A organização da } \\
\text { informação nos sites das } \\
\text { TVs universitárias públicas } \\
\text { brasileiras }\end{array}$ & $\begin{array}{c}\text { José Carlos Mardegan, } \\
\text { Brígida Maria Nogueira } \\
\text { Cervantes }\end{array}$ & 2016 \\
\hline $\begin{array}{l}\text { Mecanismos de busca de } \\
\text { jurisprudência: um } \\
\text { instrumento para a } \\
\text { organização do } \\
\text { conhecimento e } \\
\text { recuperação da informação } \\
\text { no ambiente jurídico virtual }\end{array}$ & $\begin{array}{c}\text { Tânia da Costa } \\
\text { Calheiros, Silvana } \\
\text { Drumond Monteiro }\end{array}$ & 2017 \\
\hline
\end{tabular}

Fonte: Elaborado pelos autores.

Já a segunda tabela diz respeito a Web Semântica e indexação enquanto atividades de profissionais, bem como usuários e a normatização do processo de indexação, temática recorrente e fundamental no escopo da organização do conhecimento.

Quadro 2- Artigos da dimensão aplicada Web Semântica e Indexação

\begin{tabular}{|c|c|c|}
\hline Título & Autor & Ano de Publicação \\
\hline Os fundamentos da $\mathrm{Web}$ & Flávia Rodrigues Elias & \\
\hline Semântica como & Nunes, Benildes Coura & \\
\hline ferramentas de auxílio para & Moreira dos Santos & 2020 \\
\hline as demandas da Sociedade & Maculan, Mauricio & \\
\hline da Informação & Barcellos Almeida & \\
\hline $\begin{array}{l}\text { A elaboração de resumos } \\
\text { documentários como }\end{array}$ & $\begin{array}{l}\text { Lais Pereira de Oliveira, } \\
\text { Daniel Martínez-Ávila, }\end{array}$ & 2020 \\
\hline
\end{tabular}




\begin{tabular}{|c|c|c|}
\hline $\begin{array}{c}\text { atividade do tratamento } \\
\text { temático da informação na } \\
\text { prática profissional } \\
\text { bibliotecária }\end{array}$ & $\begin{array}{c}\text { José Augusto Chaves } \\
\text { Guimarães }\end{array}$ & \\
\hline $\begin{array}{c}\text { A Organização da } \\
\text { informação e a } \\
\text { comunicação científica: } \\
\text { implicações para os } \\
\text { profissionais e usuários da } \\
\text { informação }\end{array}$ & Gisele Dziekaniak & 2010 \\
\hline $\begin{array}{c}\text { Análise e indexação de } \\
\text { imagens na rede Flickr }\end{array}$ & $\begin{array}{c}\text { Rafael Alves de Oliveira, } \\
\text { Luciane Paula Vital }\end{array}$ & 2015 \\
\hline $\begin{array}{c}\text { Método de normalização } \\
\text { de sintagmas nominais na } \\
\text { indexação automática }\end{array}$ & $\begin{array}{c}\text { Renato Fernandes } \\
\text { Corrêa, Victor Galvão } \\
\text { Celerino }\end{array}$ & 2019 \\
\hline $\begin{array}{c}\text { A análise de logs como } \\
\text { estratégia para a realização } \\
\text { da garantia do usuário }\end{array}$ & $\begin{array}{c}\text { Rita do Carmo Ferreira } \\
\text { Laipelt }\end{array}$ & 2015 \\
\hline \multicolumn{2}{|c|}{ Fonte: Elaborado pelos autores. } \\
\hline
\end{tabular}

A terceira tabela diz respeito a organização do conhecimento e arquivologia que tem discutido no contexto da Em Questão situações de aplicação de sistemas de organização do conhecimento à realidade dos arquivos, bem como discussões epistemológicas a respeito da inserção da Arquivologia no contexto da organização do conhecimento, sinalizando ser um periódico que também está atrelado aos estudos brasileiros recentes sobre a temática (BARROS; SOUSA, 2019a, 2019b).

Quadro 3- Artigos da dimensão Aplicada/Epistemológica Arquivologia e Organização do Conhecimento

\begin{tabular}{|c|c|c|}
\hline Título & Autor & Ano de Publicação \\
\hline $\begin{array}{c}\text { O tratamento temático da } \\
\text { informação em } \\
\text { instrumentos normativos } \\
\text { de descrição arquivística }\end{array}$ & $\begin{array}{c}\text { Leolíbia Luana Linden, } \\
\text { Marisa Bräscher }\end{array}$ & 2018 \\
\hline $\begin{array}{c}\text { Organização e } \\
\text { representação do } \\
\text { conhecimento arquivístico: } \\
\text { em busca de um método } \\
\text { para construção de tesauro } \\
\text { funcional }\end{array}$ & $\begin{array}{c}\text { Maíra Fernandes Alencar, } \\
\text { Brígida Maria Nogueira } \\
\text { Cervantes }\end{array}$ & 2019 \\
\hline $\begin{array}{c}\text { A Diplomática } \\
\text { contemporânea como }\end{array}$ & $\begin{array}{c}\text { Mônica Maria de Pádua } \\
\text { Souto da Cunha, Fábio }\end{array}$ & 2014 \\
\hline
\end{tabular}




\begin{tabular}{|c|c|c|}
\hline $\begin{array}{c}\text { instrumento para a } \\
\text { organização da informação } \\
\text { em arquivos }\end{array}$ & Silva Mascarenhas & \\
\hline $\begin{array}{c}\text { Proposta de uma } \\
\text { ferramenta para } \\
\text { classificação arquivística } \\
\text { com base em ontologias }\end{array}$ & $\begin{array}{c}\text { Daniel Libonati Gomes, } \\
\text { Thiago Henrique Bragato } \\
\text { Barros, Renato Tarciso } \\
\text { Barbosa de Sousa, } \\
\text { Roberto Lopes dos Santos } \\
\text { Junior }\end{array}$ & 2020 \\
\hline $\begin{array}{l}\text { A indexação de assunto em } \\
\text { documentos arquivísticos: } \\
\text { convergências e } \\
\text { divergências em artigos } \\
\text { internacionais }\end{array}$ & $\begin{array}{l}\text { Graziela Martins de } \\
\text { Medeiros, Marisa } \\
\text { Bräscher, William } \\
\text { Barbosa Vianna }\end{array}$ & 2017 \\
\hline
\end{tabular}

Fonte: Elaborado pelos autores.

No contexto do próximo quadro, temos trabalhos que discutem questões de categorização, elaboração, construção de sistemas de organização do conhecimento por meio de taxonomias, tesauros e ontologias, os instrumentos de organização e sua escada semântica (ZENG, 2008).

Quadro 4- Artigos da dimensão Aplicada Sistemas de Organização do Conhecimento

\begin{tabular}{|c|c|c|}
\hline Título & Autor & $\begin{array}{c}\text { Ano de } \\
\text { Publicação }\end{array}$ \\
\hline $\begin{array}{c}\text { Uma proposta de } \\
\text { taxonomia para a } \\
\text { categorização das } \\
\text { falhas no ambiente das } \\
\text { cadeias de suprimentos }\end{array}$ & $\begin{array}{c}\text { Mauricio Plaza-Carvajal, Moisés } \\
\text { Dutra, Douglas Macedo }\end{array}$ & 2017 \\
\hline $\begin{array}{c}\text { Análise dos modelos } \\
\text { colaborativos de } \\
\text { softwares para edição } \\
\text { de ontologias por meio } \\
\text { do Modelo 4C de } \\
\text { Colaboração }\end{array}$ & $\begin{array}{c}\text { Mapes Martins, Joyce Siqueira, } \\
\text { Douglas Veronez Santana }\end{array}$ & 2019 \\
\hline $\begin{array}{c}\text { Onto4AllEditor: um } \\
\text { editor web gráfico para } \\
\text { construção de } \\
\text { ontologias por todos os } \\
\text { tipos de usuários da } \\
\text { informação }\end{array}$ & $\begin{array}{c}\text { Fabrício Martins Mendonça, } \\
\text { Lucas Piazzi Castro, Jairo }\end{array}$ & \\
\hline $\begin{array}{c}\text { Orancisco Souza, Maurício } \\
\text { Barcellos Almeida, Eduardo } \\
\text { Ribeiro Felipe }\end{array}$ & 2021 \\
informização da & Fabrício Martins Mendonça, & 2019 \\
\hline
\end{tabular}




\begin{tabular}{|c|c|c|}
\hline $\begin{array}{c}\text { processos de } \\
\text { transformação digital }\end{array}$ & \\
\hline $\begin{array}{c}\text { Taxonomias, ontologias } \\
\text { e tesauros: } \\
\text { possibilidades de } \\
\text { contribuição para o } \\
\text { processo de Engenharia } \\
\text { de Requisitos }\end{array}$ & $\begin{array}{c}\text { Priscila Basto Fagundes, Gislaine } \\
\text { Parra Freund, Luciane Paula } \\
\text { Vouglas Dyllon Jeronimo de } \\
\text { Dacedo }\end{array}$ & 2020 \\
\hline
\end{tabular}

Fonte: Elaborado pelos autores.

No contexto do quadro 5, temos trabalhos que discutem questões relacionadas a teóricos ou apropriação de teorias específicas pela área de organização do conhecimento.

Quadro 5 - Artigos da dimensão epistemológica Teóricos da Organização do Conhecimento

\begin{tabular}{|c|c|c|}
\hline Título & Autor & Ano de publicação \\
\hline $\begin{array}{c}\text { Julius Otto Kaiser para os } \\
\text { estudos de Bibliografia e } \\
\text { Documentação para as } \\
\text { demandas da Sociedade da } \\
\text { Informação }\end{array}$ & Rodrigo de Sales & 2019 \\
\hline $\begin{array}{c}\text { Mundaneum e Biblioteca } \\
\text { Digital Mundial: relações } \\
\text { possíveis? }\end{array}$ & $\begin{array}{c}\text { Zaira Regina Zafalon, } \\
\text { Mariana Nóbrega de Sá }\end{array}$ & 2019 \\
\hline $\begin{array}{c}\text { A relação entre a memória } \\
\text { social e sociocognição: } \\
\text { busca do contexto social na } \\
\text { Organização do } \\
\text { Conhecimento }\end{array}$ & $\begin{array}{c}\text { Juliana Rabelo do } \\
\text { Carmo, Cezar Karpinski, } \\
\text { Marisa Bräscher }\end{array}$ & 2018 \\
\hline
\end{tabular}

Fonte: Elaborado pelos autores.

Por fim, trabalhos que buscam por meio de estudos sistemáticos ou métricos mensurar a produção em organização em diferentes contextos visando estabelecer o estado da área nas áreas que analisa.

Quadro 6 - Artigos da dimensão epistemológica Estudos Métricos e Sistemáticos em Organização do Conhecimento

\begin{tabular}{|c|c|c|}
\hline Título & Autor & Ano de Publicação \\
\hline Produção e colaboração & Roberta Cristina Dal’ & \\
científica em Organização e & Evedove Tartarotti, & \\
Representação do & Mariângela Spotti Lopes & 2016 \\
Conhecimento: análise & Fujita & \\
bibliométrica do GT2 do & & \\
\hline
\end{tabular}




\begin{tabular}{|c|c|c|}
\hline $\begin{array}{c}\text { ENANCIB no período de } \\
2009 \text { a } 2014\end{array}$ & & \\
\hline $\begin{array}{c}\text { Organização do } \\
\text { conhecimento: } \\
\text { uma análise conceitual nos } \\
\text { anais do ENANCIB }\end{array}$ & $\begin{array}{c}\text { Lígia Maria Arruda Café, } \\
\text { Camila Monteiro de } \\
\text { Barros, Manuela Soares } \\
\text { da Fonseca }\end{array}$ & 2014 \\
\hline $\begin{array}{l}\text { Autoria e pesquisa em } \\
\text { Organização do } \\
\text { Conhecimento: análise da } \\
\text { produção científica em } \\
\text { Ciência da Informação }\end{array}$ & $\begin{array}{c}\text { Leilah Santiago Bufrem, } \\
\text { Juliana Lazzarotto } \\
\text { Freitas, Bruna Silva } \\
\text { Nascimento }\end{array}$ & 2014 \\
\hline $\begin{array}{l}\text { A política de indexação nos } \\
\text { estudos publicados na área } \\
\text { de Biblioteconomia e } \\
\text { Ciência da Informação: } \\
\text { uma revisão sistemática de } \\
\text { literatura }\end{array}$ & $\begin{array}{l}\text { Rainner Finelli Gomes, } \\
\text { Gercina Ângela de Lima }\end{array}$ & 2021 \\
\hline $\begin{array}{l}\text { Análise de cocitação de } \\
\text { autores: uma aplicação em } \\
\text { estudos de indexação }\end{array}$ & $\begin{array}{c}\text { Luciana Beatriz } \\
\text { Piovezan, Mariângela } \\
\text { Spotti Lopes Fujita }\end{array}$ & 2014 \\
\hline $\begin{array}{c}\text { Tendências nos estudos de } \\
\text { Representação Temática da } \\
\text { Informação: uma revisão } \\
\text { integrativa dos artigos } \\
\text { científicos indexados na } \\
\text { Brapci }\end{array}$ & $\begin{array}{c}\text { Camila Regina de } \\
\text { Oliveira Rabelo, Virgínia } \\
\text { Bentes Pinto }\end{array}$ & 2019 \\
\hline
\end{tabular}

No contexto do próximo quadro, temos o único trabalho que apresenta questões relacionadas a dimensão cultural da ORC na medida em que descreve a linguagem de uma obra literária para fins de registro da representação de aspectos sociais a serem organizados em uma categorização, neste caso específico em mapas conceituais.

Quadro 7 - Artigo da dimensão cultural Literatura e Organização do Conhecimento

\begin{tabular}{|c|c|c|}
\hline Título & Autor & Ano de Publicação \\
\hline As poéticas de Abidoral & Ermeson Nathan Pereira & \\
Jamacaru enquanto registro & Alves; Anna Elizabeth & 2021 \\
de memória e representação & Galvão Coutinho Correia & \\
\hline
\end{tabular}

Fonte: Elaborado pelos autores.

Conforme apresentado ao longo dos quadros aqui esquematizados, é possível perceber que no domino da Em Questão temáticas que são caras e 
fundamentais para organização do conhecimento presentes em suas variadas vertentes. Observa-se, ainda, o incremento da publicação de textos da área nos últimos dez anos, nenhum dos artigos publicados é anterior ao ano de 2010, o que sinaliza na verdade a predominância de textos da área de comunicação ou da área de comunicação científica no período anterior. A mudança editorial para textos exclusivamente da Ciência da Informação a partir de 2014 sinaliza o crescimento da produção da área a partir de 2014 e isso também acontece no contexto da organização do conhecimento, abaixo fez-se um gráfico a fim de visualizar essa situação.

Gráfico 3- Números de artigos por ano de publicação



Fonte: Elaborado pelos autores.

Conforme o gráfico acima, fica evidente que a partir do ano de 2014 os artigos da área de organização do conhecimento atingem uma regularidade de presença em todos os anos seguintes com uma média de 4 artigos por ano.

Tendo como base os preceitos da análise de domínio e da própria trajetória da organização do conhecimento, utilizando a ferramenta Sketch Engine construiu-se grafos, baseados na análise dos verbos e contrações atrelados aos 30 artigos, a partir do entendimento que o léxico, neste caso, pressupõe ações e relacionamentos entre os enunciados-pivô elencados.

O Sketch Engine, é um software cheio de ferramentas desenvolvido pelo lexicógrafo e linguísta de corpus, Adam Kilgarriff e Pavel Rychly. Como uma 
ferramenta que busca construir corpos léxicos para análises, semânticas e lexicográficas das mais variadas formas, utilizamo-as para o nosso corpus de 30 de artigos constituído de um total de 228 mil palavras, buscando relacionar os termos "Indexação", "Organização do Conhecimento", "Organização da Informação", "Sistemas de Organização do Conhecimento", "Representação Documental", "Representação do Conhecimento", "Representação da Informação" "Representação e Organização do Conhecimento", "Taxonomia", "Tesauro" e "Ontologia", com seus conceitos, a fim de identificar como essa comunidade compreende esses conceitos fundamenteis para a organização do conhecimento. No caso da ferramenta os termos são compreendidos como lexemas, que de acordo com Dubois (2014) são a unidade mínima distintiva do sistema semântico de uma língua que reúne todas as flexões de uma mesma palavra, ou seja, sistemas possuem categorias distintivas, como no caso Sistemas de compras, sistemas de prontuários etc., seguiremos a partir daqui analisado as figuras dos lexemas.

Figura 1 - Lexema de informação no corpus de organização do conhecimento da Em Questão de 2003-2021



Fonte: Elaborado pelos autores por meio do software sketch engine.

Do ponto de vista do corpus analisado, informação está atrelada aos processo de organização, recuperação, representação, compartilhamento e conteúdo, evidenciando a premissa básica da informação para a organização, uma informação que é institucionalizada e socialmente referenciada e que faz parte dos processos de organização. 
Figura 2 - Lexema de Sistema no corpus de organização do conhecimento da Em Questão de 2003-2021

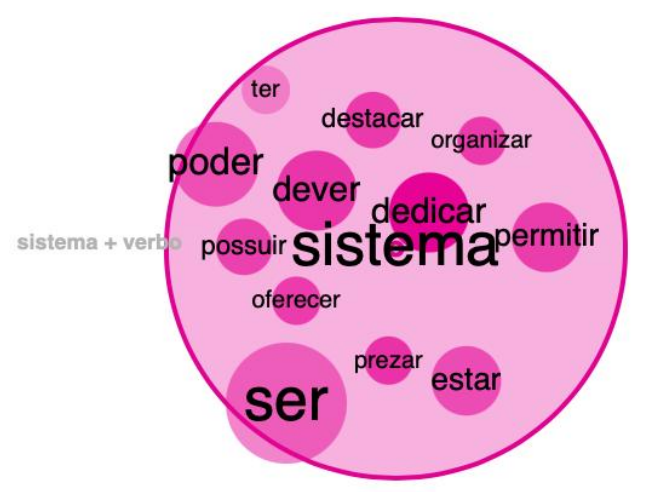

Fonte: Elaborado pelos autores por meio do software sketch engine.

Por meio do corpus é possível perceber, que para essa comunidade, os sistemas de organização do conhecimento organizam, permitem organizar, oferecem, prezam, ou seja, estabelecem um regramento para o tratamento da informação.

Figura 3 - Lexema de conhecimento no corpus de organização do conhecimento da Em Questão de 2003-2021



Fonte: Elaborado pelos autores por meio do software sketch engine.

Por meio do corpus é possível perceber, que para essa comunidade o conhecimento está atrelado à modelagem, à construção de sistemas, ao compartilhamento e disseminação de informação, ao conhecimento organizado e socialmente referenciado e representado, ou seja, conhecimento está atrelado à atividade de organização a partir de sistemas e da modelagem de domínios. 
Figura 4 - Lexema de recuperação no corpus de organização do conhecimento da Em Questão de 2003-2021



Fonte: Elaborado pelos autores por meio do software sketch engine.

Por meio do corpus é possível perceber, que para essa comunidade,a recuperação está atrelada ao processo de representação a medida que será facilitada, viabilizada e garantida por esse processo, ou seja, a recuperação está atrelada a representação.

Figura 4 - Lexema de tesauro no corpus de organização do conhecimento da Em Questão de 2003-2021

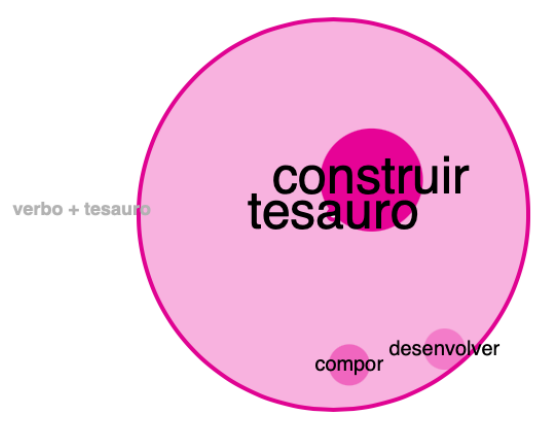

Fonte: Elaborado pelos autores por meio do software sketch engine.

Como os textos que trabalham tesauro são uma minoria no corpus levantado, os verbos atrelados aos tesauros são menores, porém a construção de tesauros parece com uma tendência desta comunidade em menor grau de frequência a composição e por fim o seu desenvolvimento. Neste sentido, o tesauro enquanto um SOC, é compreendido como algo que deve ser construído, composto e/ou desenvolvido. 
Figura 5 - Lexema de taxonomia no corpus de organização do conhecimento da Em Questão de 2003-2021

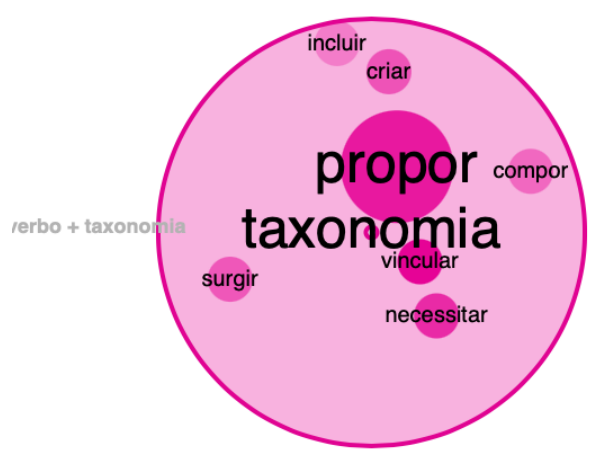

Fonte: Elaborado pelos autores por meio do software sketch engine.

Por outro lado, quando falamos de taxonomias, ao invés da contrução, a tendência maior dos textos é como uma proposição de SOC, ou seja, por ser uma ferramenta mais hierárquica do que semântica, que é proposta complementando processos de representação temática.

Figura 6 - Lexema de ontologia no corpus de organização do conhecimento da Em Questão 2003-2021



Fonte: Elaborado pelos autores por meio do software sketch engine.

Já em relação às ontologias o SOC mais presente no corpus analisado, são criadas, desenvolvidas e selecionadas, justamente por ser um SOC mais comprometido semanticamente e que busca por meio de sua concepção relacionar termos e conceitos de modo a serem lidos por computadores, 
atrelando conhecimento às ontologias encontra-se produzidas, registradas , socializadas e pode ser adquiridas

Figura 7 - Lexema de representação no corpus de organização do conhecimento da Em Questão
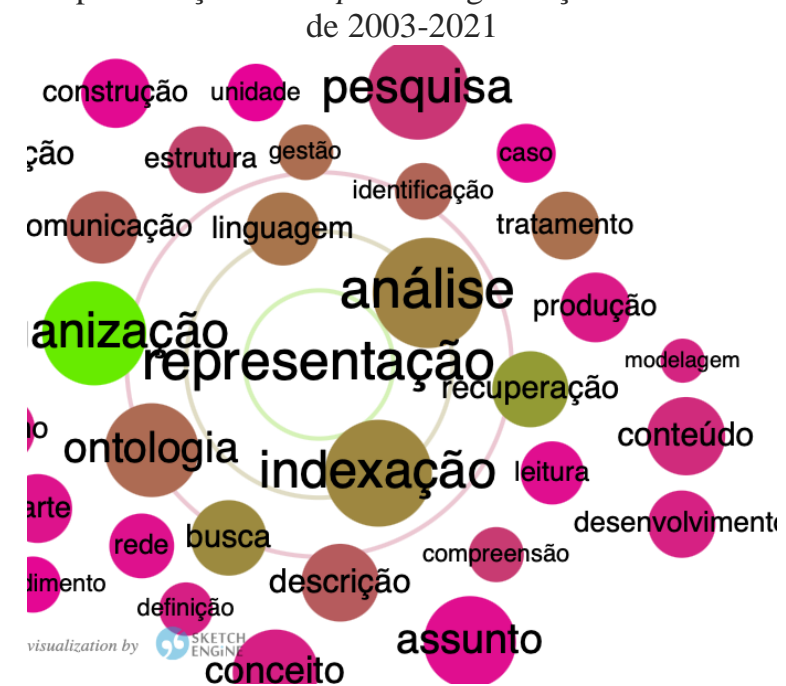

Fonte: Elaborado pelos autores por meio do software Sketch Engine.

Do ponto de vista do termo representação, sua conceituação é mais ampla justamente por ser um termo transversal ao domínio que assume múltiplas conceituações, principalmente atrelada ao processo de representação documental, elaboração de socs, indexações, linguagens. Fica evidente a presença das ontologias no lexema justamente pelo que foi destacado anteriormente, trata-se, ao menos na comunidade analisada como o SOC com maior interesse e produção de artigos e pesquisas. Acreditamos que isso se deve à completude das ontologias enquanto ferramenta de organização e representação, em relação especialmente ao termo representação, à recuperação, indexação, busca de linguagens e análise parecem como centrais e anexos à conceituação de representação. 
Figura 8 - Lexemas de recuperação/conhecimento no corpus de organização do conhecimento da

Em Questão de 2003-2021



Fonte: Elaborado pelos autores por meio do software Sketch Engine

$\mathrm{Na}$ junção dos lexemas recuperação e conhecimento fica evidente a relação entre tornar possível a construção, disseminação e modelagem do conhecimento, uma vez que a recuperação qualifica, facilita, viabilizada e é visada para tal.

Figura 9 - Lexemas de recuperação/conhecimento no corpus de organização do conhecimento da Em Questão de 2003-2021

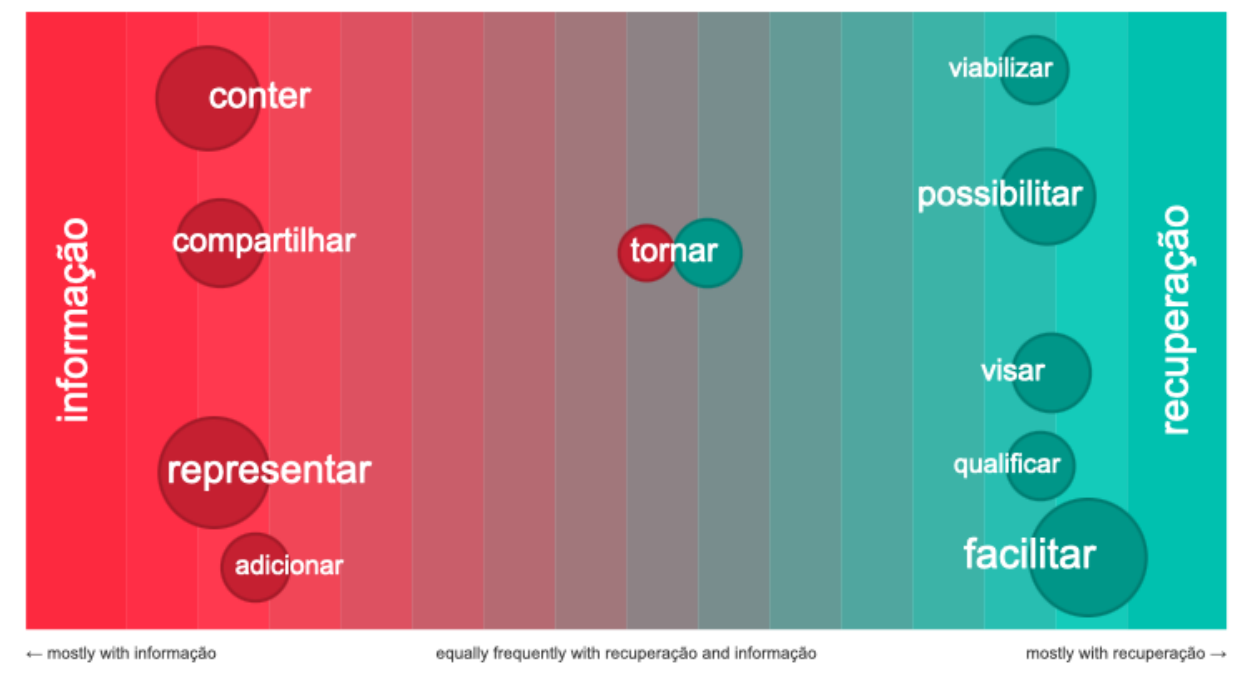

Fonte: Elaborado pelos autores por meio do software Sketch Engine. 
Na junção dos lexemas recuperação e informação fica evidente a relação não com a concepção, como no caso anterior, mas com o processo de representação da informação possibilitada, pela recuperação tornando possível o compartilhamento da informação.

Figura 10 - Lexemas de indexação no corpus de organização do conhecimento da Em Questão de 2003-2021
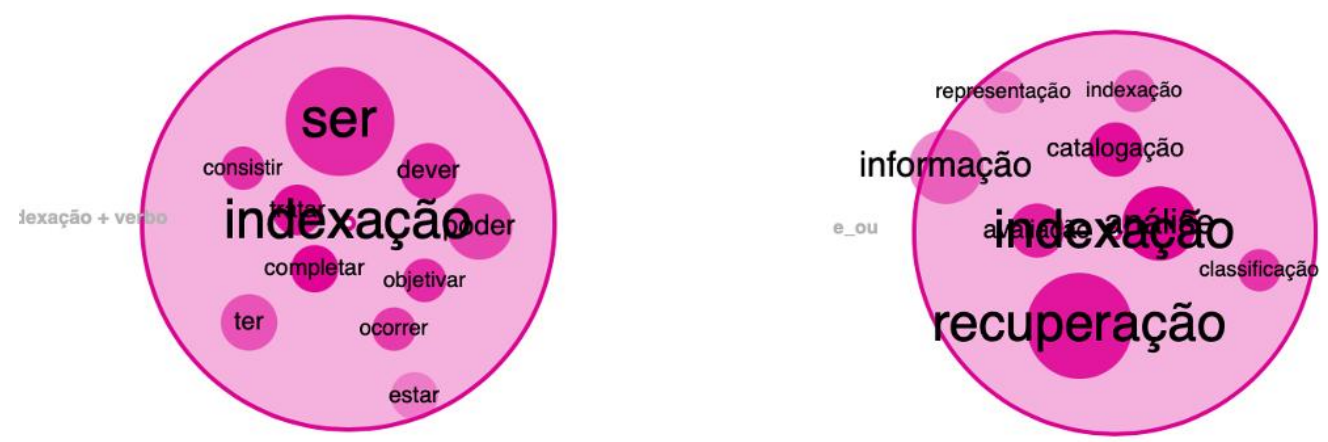

Fonte: Elaborado pelos autores por meio do software sketch engine.

A indexação está presente enquanto termo e seus conceitos quase na totalidade do corpus, justamente pela tradição do uso do termo para os processos de representação temática no contexto da Ciência da Informação no Brasil. Na figura 10 em que apresentamos uma comparação entre lexemas, está presente a indexação enquanto um processo e uma atividade, que é objetiva, construída, consiste em um procedimento passo a passo e decorre de um processo de leitura documentária. Em seus sinônimos e contrações estão atreladas a recuperação, classificação e catalogação.

A partir da análise epistemológica, temática, temporal e semântica, fica evidente o que caracteriza essa comunidade e quais são as características dos trabalhos apresentados.

Primeiro trata-se de uma comunidade que pela mudança editorial ocorrida em 2014, possui maior espaço para discussão de temas caros à organização do conhecimento, são discutidos na maioria temáticas aplicas ou epistemológicas do domínio. Atrelado a isso surgem as temáticas dos sistemas de organização do conhecimento, e sua complexidade de construção, elaboração e uso. Dá-se destaque especialmente para as ontologias, o SOC mais presente na 
comunidade e que congrega uma comunidade maior de estudos nas mais diversas áreas.

Importante sinalizar também a presença das relações entre organização do conhecimento com arquivologia, em um corpus de 30 textos 5 estão atreladas as relações entre arquivologia, organização do conhecimento e socs, as ontologias parecem mais uma vez em um estudo (GOMES et al., 2020).

Uma lacuna apresentada se dá na escassa presença de texto das temáticas culturais da organização do conhecimento, situação já destacada em outros estudos citados anteriormente. Assim, compreende-se que essa lacuna não é uma lacuna da Em Questão, mas uma lacuna da organização do conhecimento no contexto brasileiro.

Sinaliza-se a presença de estudos em domínios específicos, especialmente da informação no domínio jurídico, essa constatação não era imaginada no início deste estudo.

Acredita-se que esta análise contribui para a definição do domínio da organização do conhecimento na comunidade estudada, bem como auxilia no processo editorial da revista, à medida que ela se torna um espaço importante para as pesquisas desse campo.

\section{Considerações Finais}

Buscou-se, neste artigo, apresentar, evidenciar e explorar a comunidade discursiva em organização do conhecimento no contexto do periódico Em Questão, a análise construiu-se a partir de uma análise de domínio em suas abordagens epistemológicas, discursivas e semânticas no sentido de apresentar e explorar qualitativamente os estudos e temáticas do corpus construído.

Foram analisados 30 artigos produzidos nos últimos 11 anos no periódico ainda que o recorte temporal se dê nos últimos 18 anos. A presença de textos do domínio da organização do conhecimento só começam a aparecer a partir de 2010 e uma crescente de textos a partir de 2014 quando a revista passa a receber exclusivamente textos da área de Ciência da Informação essa mudança, ao menos no corpus analisado, foi fundamental para o aparecimento 
de textos da área de organização, bem como das temáticas centrais da área, que a partir daí passam a surgir.

Discute-se também por meio do corpus, as principais temáticas trabalhadas, as principais discussões a respeito de conceitos-chave da área no domínio, evidenciando a trajetória a partir dos artigos publicados e do próprio periódico.

Compreende-se também, que por tratar-se de um estudo que visou utilizar de ferramentas da linguística de corpus, apresenta uma inovação para as análises de domínios que poderão ocorrer a partir daqui.Esse exercício era algo que os autores se propunham e conseguiram cumprir no presente estudo. A intenção é explorar mais essas ferramentas em corpus de domínios mais abrangentes que congreguem mais periódicos a fim de compreender com maior profundidade qual é a comunidade brasileira em organização do conhecimento, o primeiro passo, neste caso, já foi dado.

\section{Referências}

BARITÉ, M. Diccionario de Organización del Conocimiento: Clasificación, Indización. Montevideo: CSIC, 2015.

BARROS, T. H. B. A análise discurso de Michel Pêcheux e a organização do conhecimento: possiblidades teórico-metodológicas In: AMORIN, I; SALES, R. Ensaios em Organização do Conhecimento, Florianópolis:UDESC, 2021, p. 61-78.

BARROS, T. H. B.; SOUSA. R. T. B. Archival Science and Knowledge Organization: Mapping Methodological Relationships. Knowledge

Organization, Frankfurt, v. 46, n. 7, p. 493-501, 2019a.

BARROS, T. H. B.; SOUSA. R. T. B. Organização do conhecimento e arquivologia: abordagens metodológicas. Informação \& Informação, Londrina, v. 24, n. 2, p. 76-92, 2019 b.

BRASCHER, M.; CAFÉ, L. Organização da informação ou organização do conhecimento? In: LARA, M. L. G.; SMIT, J. (Orgs.). Temas de pesquisa em Ciência da Informação no Brasil. São Paulo: Escola de Comunicação e Artes/USP, 2010. P. 1-14

DAHLBERG, I. Knowledge organization: a new science? Knowledge Organization, Frankfurt, v. 33, n. 1, p. 11-19, 2006. 
DUBOIS, J. Dicionário de Linguística. São Paulo: Cultrix, 2014.

EVANGELISTA, I. V.; BARROS, T. H. B. Bragato; MORAES, J. B. E. Uma análise do discurso da dimensão cultural da International Society for Knowledge Organization. Informacao \& Sociedade: Estudos, João Pessoa, v. 28, p. 37-47, 2018.

GOMES. D. L.; BARROS, T. H. B.; SOUSA, R. T. B.; SANTOS JUNIOR, R. L. Proposta de uma Ferramenta para Classificação Arquivística com Base em Ontologias. Em Questão, Porto Alegre, v. 26, n. 1, p. 351-374, 2020.

GUIMARÃES, J. A. C. Análise de domínio como perspectiva metodológica em organização da informação. Ciência da Informação, Brasília, v. 43, n. 1, p. 13$21,2015$.

GUIMARÃES, J. A. C.; TOGNOLI, N. B. Provenance as a Domain Analysis Approach in Archival Knowledge Organization. Knowledge Organization, Frankfurt, v. 42, n. 8, p. 562-69, 2015.

HJØRLAND, B. Domain analysis in Information Science: Eleven approaches traditional well as innovative. Journal of Documentation, Bingley, v.58, n.4, p.422-462, 2002.

HJØRLAND, B. Domain analysis In: HJØRLAND, B.; GNOLI, C. (Org.) Encyclopedia of Knowledge Organization, [s. l.], v. 44, n. 6, p.20-80, 2017.

HJØRLAND, B. Knowledge Organization (KO). In: HJØRLAND, B.; GNOLI, C. (Orgs.). Encyclopedia of Knowledge Organization, [s. l.], v. 43, n. 6, p.475-484, 2016.

HJØRLAND, B. What is Knowledge Organization (KO)? Knowledge Organization, Frankfurt, v. 35, n. 2, p. 86-101, 2008.

HJØRLAND, B.; ALBRECHTSEN, H. Toward a new horizon in Information Science: domain-analysis. Journal of the American Society for Information Science, [s. l.], v.46, n. 6, p. 400-425, Jul. 1995.

HODGE, G. Systems of knowledge organization for digital libraries: beyond traditional authority files. Washington: ERIC, 2001.

MAI, J-E. Analysis in indexing: Document and domain centered approaches. Information processing and management, [s. l.], v. 41, p. 599$611,2005$.

MAZZOCCHI, F. Knowledge organization system (KOS). In: ISKO.

Encyclopedia of Knowledge Organization, [s. l.], v. 45, n. 1, p. 54-78. 2018. 
ØROM, A. Knowledge organization in the domain of art studies: History, transition and conceptual changes. Knowledge Organization, Frankfurt, v. 30, n. 3-4 p.128-143, 2003.

SMIRAGLIA, R. P. Domain Analysis for Knowledge Organization. New York: Springer, 2015.

TENNIS, J. T. Two axes of domains for domain analysis. Knowledge Organization, Frankfurt, v. 30, n. 3-4 p. 191-195, 2002

TENNIS, J. T. What does a domain analysis look like in form, function, and genre? Brazilian Journal of Information Science, Marília, v. 6, n. 1, p. 3-14, 2012.

TOGNOLI, N.; SILVA, A. M. S.; SILVA, A. P. Organização do Conhecimento e Arquivologia: uma análise de domínio nos periódicos Knowledge

Organization e Scire. Informação \& Informação, Londrina, v. 24, n. 3, p. 5277, set./dez. 2019.

\section{APÊNDICE A - CORPUS DE ANÁLISE}

ALENCAR, M. F., \& CERVANTES, B. M. N. Organização e representação do conhecimento arquivístico: em busca de um método para construção de tesauro funcional. Em Questão, Porto Alegre, v. 25, n. 1, p. 368-389, 2019.

ALVES DE OLIVEIRA, R.; VITAL, L. P. Análise e indexação de imagens na rede Flickr. Em Questão, Porto Alegre, v. 21, n. 2, p. 7-30, 2015

BUFREM, L. S., FREITAS, J. L.; NASCIMENTO, B. S. Autoria e pesquisa em Organização do Conhecimento: análise da produção científica em Ciência da Informação. Em Questão, Porto Alegre, v. 20, n. 3, p. 10-30, 2014.

CAFÉ, L., BARROS, C.; FONSECA, M. Organização do conhecimento: uma análise conceitual nos anais do ENANCIB. Em Questão, Porto Alegre, v. 20, n. 1, p. 1-27, 2014.

CALHEIROS, T. D. C.; MONTEIRO, S. D. Mecanismos de busca de jurisprudência: um instrumento para a organização do conhecimento e recuperação da informação no ambiente jurídico virtual. Em Questão, Porto Alegre, v. 23, n. 2. p. 146.-166, 2017

CORRÊA, R. F.; CELERINO, V. G. Método de normalização de sintagmas nominais na indexação automática. Em Questão, Porto Alegre, v.25, n. 1, p. 321-344, 2019. 
DO CARMO, J. R., KARPINSKI, C.; BRÄSCHER, M. A relação entre a memória social e sociocognição: busca do contexto social na Organização do Conhecimento. Em Questão, Porto Alegre, v. 24, n. 1, p. 65-85, 2018.

DZIEKANIAK, G. Organização da informação e a comunicação científica: implicações para os profissionais e usuários da informação Em Questão, Porto Alegre, v. 16, n. 1, p. 45-59, 2010.

FAGUNDES, P. B., FREUND, G. P., VITAL, L. P., BARROS, C. M.; JERONIMO DE MACEDO, D. D. Taxonomias, ontologias e tesauros: possibilidades de contribuição para o processo de Engenharia de Requisitos. Em Questão, Porto Alegre, v. 26, n. 1, p. 237-254, 2020.

FERREIRA, A. C.; MACULAN, B. C. M. S. Análise de assunto de acórdãos jurisprudenciais. Em Questão, Porto Alegre, v. 24, n. 1, p. 85-116, 2018.

FERREIRA, A. C.; MACULAN, B. C. M. DOS S. Metodologia para a análise de assunto de acórdãos no contexto do controle externo: proposta de um modelo de leitura técnica. Em Questão, Porto Alegre, v. 25, n. 3, p. 99-131, 2019.

GOMES, D. L., BARROS, T. H. B., SOUSA, R. T. B. DE; SANTOS JUNIOR, R. L. dos. Proposta de uma ferramenta para classificação arquivística com base em ontologias. Em Questão, Porto Alegre, v. 26, n. 1, p. 351-374, 2020.

GOMES, R. F.; LIMA, G. Â. de. Importância da política de indexação para as unidades de informação: uma revisão sistemática da literatura. Em Questão, Porto Alegre, v. 27, n. 1, p. 210-236, 2020.

LAIPELT, R. C. F. A. Análise de logs como estratégia para a realização da garantia do usuário. Em Questão, Porto Alegre, v. 21, n. 3, p. 150-170, 2015.

LINDEN, L. L.; BRÄSCHER, M. O tratamento temático da informação em instrumentos normativos de descrição arquivística. Em Questão, Porto Alegre, v. 24, n. 3, p. 96-124, 2018.

MARDEGAN, J. C.; NOGUEIRA CERVANTES, B. M. A organização da informação nos sites das TVs universitárias públicas brasileiras. Em Questão, Porto Alegre, v. 22, n. 1 p. 90-112, 2016.

MARIA DE PÁDUA SOUTO DA CUNHA, M.; SILVA MASCARENHAS. A Diplomática contemporânea como instrumento para a organização da informação em arquivos. Em Questão, Porto Alegre, v. 20, n. 2, p. 30-60. 2014

MEDEIROS, G. M. de; BRÄSCHER, M.; VIANNA, W. B. Indexação de assunto em documentos arquivísticos: convergências e divergências em artigos científicos internacionais. Em Questão, Porto Alegre, v. 23, n. 1, p. 154-182, 2017. 
MENDONÇA, F. M., CASTRO, L. P., SOUZA, J. F., ALMEIDA, M. B.; FELIPE, E. R. Onto4AllEditor: um editor web gráfico para construção de ontologias por todos os tipos de usuários da informação. Em Questão, Porto Alegre, v. 27, n. 3, p. 401-430, 2021.

MENDONÇA, F. M.; ZAIDAN, F. H. Ontologias para organização da informação em processos de transformação digital. Em Questão, Porto Alegre, v. 25, n. 1, p. 295-320, 2019.

NUNES, F. R. E.; MACULAN, B. C. M. S.; BARCELLOS ALMEIDA, M. Os fundamentos da Web Semântica como ferramentas de auxílio para as demandas da Sociedade da Informação. Em Questão, Porto Alegre, v. 26, v. 3, p. 224-249, 2020.

OLIVEIRA, L. P. DE; MARTÍNEZ-ÁVILA, D.; GUIMARÃES, J. A. C. A. elaboração de resumos documentários como atividade do tratamento temático da informação na prática profissional bibliotecária Em Questão, Porto Alegre, v. 26, n. 1, p. 255-277, 2020.

PEREIRA ALVES, E. N.; COUTINHO CORREIA, A. E. G. As poéticas de Abidoral Jamacaru enquanto registro de memória e representação do conhecimento. Em Questão, Porto Alegre, v. 27, n. 1, p. 59-90, 2020.

PIOVEZAN, L. B.; SPOTTI, M.; FUJITA, L. Análise de cocitação de autores: uma aplicação em estudos de indexação. Em Questão, Porto Alegre, v. 21, n. 1 p. $110-129,2015$

PLAZA-CARVAJAL, M., DUTRA, M.; MACEDO, D. Uma proposta de taxonomia para a categorização das falhas no ambiente das cadeias de suprimentos. Em Questão, Porto Alegre, v. 23, n. 3 p. 179-206, 2017.

RABELO, C. R. D. O.; PINTO, V. B. Tendências nos estudos de Representação Temática da Informação: uma revisão integrativa dos artigos científicos indexados na Brapci. Em Questão, Porto Alegre, v. 25, n. 2, p. 66-88, 2019.

SALES, R. Julius Otto Kaiser para os estudos de Bibliografia e Documentação. Em Questão, Porto Alegre, v. 25, p. 176-193, 2019.

SILVA, M. F., MARTINS, D. L., SANTANA, D. V.; SIQUEIRA, J. Análise dos modelos colaborativos de softwares para edição de ontologias por meio do Modelo 4C de Colaboração. Em Questão, Porto Alegre, v. 25, n. 1, p. 267-294, 2019.

TARTAROTTI, R. C. D. E.; FUJITA, M. S. L Produção e colaboração científica em Organização e Representação do Conhecimento: análise bibliométrica do GT2 do ENANCIB no período de 2009 a 2014. Em Questão, Porto Alegre, v. 22, n. 3, p. 136-160, 2016. 


\title{
A Domain Analysis of Knowledge Organization in the contexts of the Em Questão journal
}

\begin{abstract}
This article aims to map and analyze thematically, semantically, and discursively the articles in the field of knowledge organization published in the journal Em Questão since its migration to the SEER digital system in 2003. The thematic categories for the analyses of articles were obtained from a domain analysis. The search first took place in the journal's own database, with key terms from the area of knowledge organization. A domain analysis was carried out based on epistemological, semantic, and discursive approaches. The Sketch Engine corpus analysis software was used as a semantic analysis tool, seeking to assist in the construction of a qualitative analysis. A corpus of 30 texts was reached, in several of the central themes of the Knowledge organization area, and an analysis was carried out. Base on a thematic, temporal, semantic and discursive approach. As a result, a timeline of the themes, conceptual relationships of knowledge organization articles published more frequently over the last 18 years of the journal was organized, with an increased production in knowledge organization from 2014 onwards.
\end{abstract}

Keywords: Knowledge Organization; Domain Analysis; Semantics; Em Questão.

Recebido: 12/07/2021

Aceito: 16/07/2021

\section{Declaração de autoria}

Concepção e elaboração do estudo: Thiago H B Barros, Rita Laipelt

Coleta de dados: Thiago H B Barros, Rita Laipelt

Análise e interpretação de dados: Thiago H B Barros, Rita Laipelt

Redação: Thiago H B Barros, Rita Laipelt

Revisão crítica do manuscrito: Thiago H B Barros, Rita Laipelt 


\section{Como citar}

BARROS, Thiago Henrique Bragato; LAIPELT, Rita do Carmo Ferreira. Uma análise de domínio da área de Organização e Representação do Conhecimento no contexto do periódico Em Questão. Em Questão, Porto Alegre, v. 27, n.4, p.438-468, 2021. Doi: http://dx.doi.org/10.19132/1808-5245274.438-468 